\title{
Seating Our Patrons: A Multi-Year Approach to Creating and Assessing User Space
}

\author{
Margaret Fain and Jennifer Hughes \\ Coastal Carolina University, USA
}

\section{Introduction:}

Like many academic libraries, Kimbel Library at Coastal Carolina University has a space problem. Use of the library building increases as the student population grows, while the physical facility has barely kept pace. Between 2009 and 2018, the student population grew 27\%, from 8,100 to 10,300. In the same time period, the square footage of the library increased $38 \%$, but the actual square footage only increased from 43,000 to 61,200 square feet. In an effort to increase seating and workspaces for students, over the past nine years library staff has been conducting the Kimbel Library Space Study, which uses assessment data to effect change in floor plans and seating options. This paper outlines the process through which a longitudinal study was developed that utilizes multiple assessment measures for continual improvement of library space. Over the course of the past decade, we have utilized external studies, LibQUAL+ surveys, and internal assessments to conduct ongoing assessment and a redesign of the existing and new library space in response to increasing use of the facility by students. The ongoing impact has been to maximize space use in the library given building size restrictions and a growing student population.

\section{LibOUAL Survey One:}

The genesis of the longitudinal study was the administration of the LibQUAL climate survey in the fall of 2009. This was the first time LibQUAL has been used to measure service satisfaction at Kimbel Library. Previous surveys had been developed and administered in-house, and, while inexpensive, had not yielded the type of information needed for planning. The 2009 survey was intended to be a benchmark study, anticipating the addition of a new library addition that was currently under design. While not originally envisioned as a space use study, the combination of quantitative data and qualitative comments relating to space issues and satisfaction were put to use in both building planning and enacting immediate change on the existing facility. In order to make use of the data in the comments; we coded all comments in an Excel spreadsheet by status of responder (faculty, undergraduate, graduate), discipline, tone of comment (positive, negative, neutral), and specific survey dimension question referenced. Comments were than sorted in a variety of ways to easily see which comments related to specific questions within each dimension, which ones were negative or positive, and which type of patron made the comment. This enabled us to differentiate between needs of undergraduates, graduate students, and faculty. Pairing qualitative comments with service quality dimensions enabled us to identify specific issues that might have contributed to the overall quantitative results and provide directions for improvements.

The LibQUAL comments provided reassurance and praise for what the library was doing well; they also revealed specific areas of concern, substantiating what staff believed to be true. There were many positive comments on the availability of CDs, DVDs, computers, and printers. In the middle of the survey administration, the library's hours expanded to $24 / 5$, and initial reactions indicated that students loved the new schedule, liked the new relaxed food and drink policy, the decrease in restrictions on cell phone use, and, overall, found the library to be a great place to study. Many respondents, though, found it difficult to study in the existing library building because of high noise levels, overcrowding, limited number of study rooms, and cold temperatures. They found the facility to be dim and dingy and original furnishings from 1977 to be outdated.

The resulting data was shared with all departments who were encouraged to develop proactive responses, particularly to specific recurring issues identified through the comments. Over the next three years, seating options were increased on the first floor by removing stacks to create an open floor plan. The bound journals were relocated to the second floor, while reference and media materials were interfiled into the main stack 
collection on the second floor. Government documents were weeded and the remaining materials were moved into the main stacks. Reducing the number of collection locations improved the search functionality of the library's webpage, increased students' ability to find resources in the building, and most importantly, freed up valuable floor space. The library shifted the focus of purchase considerations to include many more e-books as space in the second floor main stacks was limited. Removing shelving units from the first floor opened up space surrounding existing columns, which already had electrical outlets, allowing more individual computer workstations to be purchased and installed around the columns. Tables were removed from the designated silent study spaces on the second floor area and relocated to the open spaces on the first floor to accommodate more collaborative study. Like many other library buildings built in the same era, the 1977 structure continually struggles to keep pace with ever-increasing electrical needs. Dozens of six-foot flat power cords were purchased to provide electrical access to the tables. It seemed that the first floor noise levels increased with the addition of more large tables and the reduction in sound-absorbing print materials, so a basic noise suppression system was installed to provide white noise throughout the entire first and second floors of the library. New lighting was installed to improve visibility and reduce electrical costs.

LibQUAL comments were also shared with the architect and incorporated into the design process for the new Learning Commons space, along with focus groups based on issues raised by the survey. The need was very clear for space that would reduce overcrowding and noise levels in the existing facility. The new space should have an inviting, updated décor including a variety of flexible seating options and natural lighting. Comments supported the need for more computers, electrical outlets, dry erase boards, and study rooms. There was also strong interest in self-checkout machines. The new addition was to be connected to the existing 1977 structure, with a focus on providing computer workspaces and study rooms for collaborative work. The new facility opened in 2012 with 84 new desktops plus 24 instructional laptops, 9 study rooms each equipped with an EnoBoard as well as large screen monitors. Furnishings provided a variety of seating styles to accommodate the needs of individuals and collaborative groups. Twenty rolling white boards were available for students for use with studying or to create personal workspaces. Booths, padded benches, and soft seating near expansive windows provided relaxed, comfortable areas for studying, while large, technologically enhanced tables were more conducive to collaborative group work. Wall and floor outlets were abundant throughout the new Bryan Information Commons, exceeding current needs in hope of meeting future needs. An enhanced white noise system was installed in the new facility, which provided volume control specific to various sections to mask the sounds of collaborative study. Though the new addition did not contain any physical library materials, construction project funding was allocated to upgrade the library's EAS security system to an RFID system that would provide desensitizing capabilities.

As part of the upgrade, the locking security gates at the exits were replaced by less obstructive gates that did not impede passage of patrons and were more visually appealing and less intrusive. To accommodate the new security system, the library's entire print and non-print collections were retagged and three selfcheckout stations and a self-check-in book drop were installed in the original library building.

\section{LIBOUAL Survey Two:}

Due to the extensive changes made to library services, policies, and building space following the LibQUAL survey, the library received an internal assessment grant to fund a follow-up study in fall semester 2012 to assess the impact of the changes. The success of the 2009 survey in creating change was the impetus for conducting the second survey. The administration of the LibQUAL Lite survey was timed to coincide with the opening of the 16,800 square foot Bryan Information Commons. This was intentional, as the 1977 side of the building still had the same furniture and carpeting as it did when it opened, despite a minimal renovation that removed walls and created the first study and instruction rooms back in 2003. Unlike the existing Kimbel Library building, the new Bryan Information Commons contained only computer workstations, collaborative study Mediascapes, and study rooms; no stacks were allowed. The LibQUAL Lite survey would assess changes made to the 1977 building since the 2009 survey, provide information on changes still needed, and provide data on student satisfaction with the new building, in particular, the increased access to computers, seating, and study room space. 
Replicating the comment analysis conducted with the 2009 LibQUAL study enabled us to compare results between the studies, despite using two different versions of LibQUAL. Again, we coded all comments in an Excel spreadsheet. We utilized the same dimension as the 2009 study, adding only whether the comment related to the Kimbel Library or Bryan Information Commons space.

While the new Bryan Information Commons was a hit with patrons, data mining the comments highlighted the specific areas of dissatisfaction, the majority of which centered on the aging furnishings and carpet on the Kimbel Library side. The flood of comments regarding the "dingy" appearance of the 1977 building in contrast to the new addition prompted the university administration to release funds to replace the carpeting for the first time since the building was opened and to approve a gradual repainting of all the walls in the Kimbel Library building the following year.

With the opening of the Bryan Information Commons, library hours went to 24/7. An administrative decision was made to close the Kimbel Library side-the one with group tables-at midnight and require all students to move to the new Bryan Information Commons. This was highly unpopular as headcounts at midnight exceeded seat space in BIC and groups already established at tables did not want to move to a space that lacked similar space. In addition, at certain hours on weekends, the Kimbel side was open and the Bryan Information Commons side was not. Student comments in LibQUAL were highly negative regarding this arrangement, which reinforced arguments that library staff had been making to treat the two buildings as one. Shortly after the comments were released to library staff, a new administrative decision was made to open the entire building as one, ensuring that all library space was available for student use 24 hours per day, 7 days per week.

\section{Kimbel Library Space Use Study:}

By 2014, building use was increasing, but we had new questions. How were the students actually using the spaces in the two buildings? Did the location of the limited outlets meet student needs? We had safety and accessibility concerns over the number and migration patterns of the electrical power strips previously purchased for the Kimbel Library building. Did we need fewer tables for group work or an increased number? Did the location of the tables matter? Visually, it was apparent that groups were using tables, but were the tables in the best location to facilitate group work and minimize noise distractions to other patrons? We had increased the number of large and small group study rooms. How were the study rooms actually being utilized? We had no way of counting room use as the provost at the time did not support using a reservation system and required that all study rooms were first come, first serve. The library was affectionately called "Club Kimbel" by the students, but was that all they were doing, socializing? Was the library a social gathering spot rather than a space for study and research in support of student achievement?

Lacking funding to conduct a third LibQUAL study and wanting to focus specifically on space use in the two buildings, a group of librarians and staff developed a space study using an ethnographic approach to address these internal concerns. An internal working group, the Library as Space Committee, had been established in 2013. This group was grappling with the lack of data while library administrators and staff had varying opinions on how and why space was being used by students and what changes would maximize space use. The space study was designed to provide data to support decision-making, based on the successful use of the LibQUAL survey data in prior years. A key consideration was that, in contrast to the LibQUAL surveys, this would be an observational study that would use library staff time but would not require any time commitment from students.

The committee read existing literature and held several meetings to define exactly what information was needed and how we might acquire it. ${ }^{1}$ Basing the study on anthropological methods, we decided to do an observational study that would track where students were working and what behaviors they were engaged in. The building was divided into five zones and every seat and workspace was identified using a floor plan, tagged, and mapped to an Excel spreadsheet. ${ }^{2} \mathrm{~A}$ list of patron behaviors was developed, with assigned codes to track activity taking place in each seat and workspace. Teams of librarians and staff surveyed the areas on a rotating schedule of days to ensure that the entire building was mapped at different times of day, including 
the overnight hours. The findings supported staff suppositions regarding building use and also provided some surprises. Use of the building was slightly higher in the "old" Kimbel Library, 54 percent compared to 47 percent in the "new" Bryan Information Commons. Students studying alone accounted for 60 percent of use, students in groups 40 percent. The seats with highest use in all five zones were, not surprisingly, those with the easiest access to electrical power outlets. With regard to what students were doing in the library, only 16 percent were actively socializing; the remainder were engaged in a variety of behaviors related to study or research.

The study confirmed that the establishment of a customer service point on the fringe of the quiet study area was a poor fit. The volume of traffic and resulting noise was detrimental to effective student use of the quiet zone. The service point was removed and consolidated into existing service points in areas that tolerated noise. Students had defined the four floors of the library by their behavior and the expectation that the library staff would reinforce the desired noise levels. The first floors, with tables, computer workstations, and service points, are for group study and a very high level of noise is tolerated by students. The second floor of the original building is designated as silent study. Students expect the second floor of the Bryan Information Commons to have lower noise levels than the first two floors but do not expect silent study in that space.

To provide better access to electrical services, the large tables were redistributed on the first floor of Kimbel Library, the group study area, to be closer to power outlets. Tables without power were labeled as such and strategically located. Soft seating was redistributed based on the traffic flow pattern. Use of the newly arranged seating options increased use of all seats on this floor. In an ongoing effort, the university administration was lobbied for new chairs, in part to reduce the student-to-seat ratio. In 2009, with a population of 8,100 students, the library student seat ratio was 18:1; in 2018, with a student population just over 10,000, the seat ratio is now 11:1.

\section{Library Services Study:}

In the fall of 2018, the "Kimbel Wants to Know" point-of-use study was launched. The focus of this study is to identify resources and services that the library can provide or improve upon. In designing this study, the authors wanted to gather responses to a wide range of questions related to the use of the building and services. A less time-intensive process was needed than using an external or observational study. While the space study yielded much useful data, the expense in staff and librarian labor was high. We decided to use comment sheets located by the service or space under review. The intention is to gather information based on real-time student use at the specific location. Weekly questions are posted and students respond by writing in or checking off options on large comment sheets. The advantage of this method is that, in the first week, we received 418 responses and 74 comments to our first question. It took us four weeks to get 668 viable LibQUAL Lite surveys in 2012. As we move forward, we will be looking to see if response rates continue at a high level or if the novelty of responding wears off over the course of the semester.

While this is a study in progress, questions will be asked about space use and we will be coding all comments to provide a comprehensive picture of unrealized needs and areas that can be improved on. Kimbel Library space is constantly in flux. We still do not "control" all the physical space in the library; several large rooms have been used as overflow adjunct faculty offices and study rooms are "borrowed" for a semester to house campus administrators while renovations are conducted on other buildings. We anticipate using the data from the new study to develop plans for accommodating new services and spaces (archives, Makerspace) and for accommodating the increasing number of students who want to use Kimbel Library and Bryan Information Commons as a hub of academic activity.

\section{Summary:}

We used quantitative measures (LibQUAL, seat use surveys, seat counts, building use counts) and qualitative measures (LibQUAL comments, survey comments) to create composite pictures of how students were actually using available space and what needs were being met or unmet. Each study was unique but built on the findings of the previous study. While the data acquired from LibQUAL was very valuable, the time and 
money commitment was high. The in-house assessments are low cost, but still require time to administer and analyze the data. We have concerns that students are increasingly less-inclined to respond to time-intensive online studies and more apt to respond to shorter on-point questions.

A culture of assessment leading to change was built from the beginning. The sheer number of positive changes enacted as a result from the initial LibQUAL study meant that, with each study, library staff were eagerly awaiting the summary data in order to enact further changes that improved space and services.

We found that students had a variety of needs and were actively creating the spaces they wanted to be in. Our task is to ensure that the physical space is conducive to the expected use. Having a willingness to move furniture and furnishings was essential, as student needs are continually evolving. By prototyping spaces and studying the results, we effected change that promoted increased usage of space and furnishings. In addition to rearranging workspaces, removing tables from quiet areas and increasing them in noise zones, and rearranging furniture to maximize access to electrical outlets, we modified policies, such as dispensing with all food and drink policies. This contributed to an atmosphere that meets the needs and desires of our student population. When designing the library addition, furniture selection was based on versatility and the ability to promote formal and informal collaborative spaces. Throughout the nine-year cycle, we assessed existing space, created and implemented changes based on the data, and assessed the changes, developing new approaches to space use with each assessment cycle. The ultimate goal is to make the best use of available square footage while balancing needs of individual access with collaborative group work areas. Physical space restrictions do not have to restrict the ability to innovate and serve students. The final result is a library that accommodates students and makes the most effective use of the limited space available.

-Copyright 2019 Margaret Fain and Jennifer Hughes

1. See Andrew Asher and Susan Miller, So You Want to do Anthropology in Your Library?: A Practical Guide to Ethnographic Research in Academic Libraries (Chicago: ERIAL Project, 2011); Margaret Brown-Sica, "Library Spaces for Urban, Diverse Commuter Students: A Participatory Action Research Project," College \& Research Libraries 73, no. 3 (May 2012): 217-231; Michele Crump, "Assess to Cultivate Your Own Library," in Meeting the Needs of Student Users in Academic Libraries: Reaching Across the Great Divide, eds. Michele Crump and LeiLani Freund (Oxford: Chandos Publishing, 2012), 69-88; Nancy Fried-Foster and Susan Gibbons, Studying Students: The Undergraduate Research Project at the University of Rochester (Chicago: ACRL, 2007).

2. Margaret Fain and Jennifer Hughes, "Gathering User Behaviors: Improving Library Space while Enhancing the Library's Profile," in Academic Libraries and the Academy: Strategies and Approaches to Demonstrate Your Value, Impact and Return on Investment, vol. 2, eds. Marwin Britto and Kirsten Kinsley (Chicago: ACRL, 2018). 